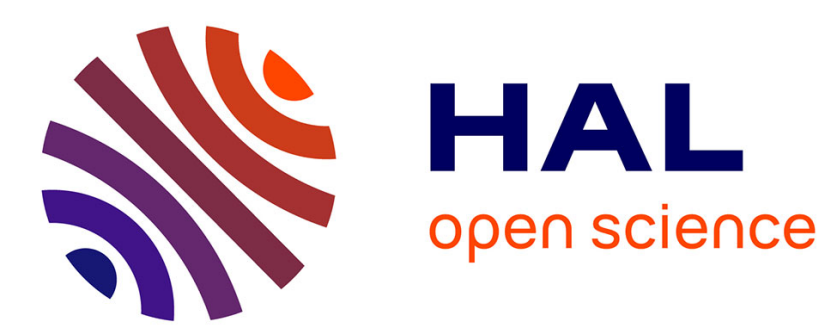

\title{
Defects creation in sapphire by swift heavy ions: a fluence depending process
}

\author{
A. Kabir, A. Meftah, J.-P. Stoquert, M. Toulemonde, I. Monnet
}

\section{To cite this version:}

A. Kabir, A. Meftah, J.-P. Stoquert, M. Toulemonde, I. Monnet. Defects creation in sapphire by swift heavy ions: a fluence depending process. The Seventh International Symposium on Swift Heavy Ions in Matter, Jun 2008, Lyon, France. hal-00282005

\section{HAL Id: hal-00282005 \\ https://hal.science/hal-00282005}

Submitted on 17 Jul 2008

HAL is a multi-disciplinary open access archive for the deposit and dissemination of scientific research documents, whether they are published or not. The documents may come from teaching and research institutions in France or abroad, or from public or private research centers.
L'archive ouverte pluridisciplinaire HAL, est destinée au dépôt et à la diffusion de documents scientifiques de niveau recherche, publiés ou non, émanant des établissements d'enseignement et de recherche français ou étrangers, des laboratoires publics ou privés. 


\title{
Defects creation in sapphire by swift heavy ions: a fluence depending process
}

\author{
A. Kabir ${ }^{1, *}$, A. Meftah ${ }^{1}$, J.P. Stoquert ${ }^{2}$, M. Toulemonde ${ }^{3}$, I. Monnet $^{3}$ \\ ${ }^{1}$ LRPCSI, Université 20 Août 55, BP 26, Route d'El-Hadaiek, Skikda, Algeria \\ ${ }^{2}$ InESS, 23, rue du Loess - BP 20 CR - F-67037 Strasbourg Cedex 02, France \\ ${ }^{3}$ CIMAP, BP 5133, 14070 Caen Cedex 05, France
}

\begin{abstract}
Single crystals of sapphire $\left(\alpha-\mathrm{Al}_{2} \mathrm{O}_{3}\right)$ were irradiated at GANIL with $0.7 \mathrm{MeV} / \mathrm{amu}$ xenon ions corresponding to an electronic stopping power of $21 \mathrm{keV} / \mathrm{nm}$. Several fluences were applied between $5 \times 10^{11}$ and $2 \times 10^{14}$ ions $/ \mathrm{cm}^{2}$. Irradiated samples were characterized using optical absorption spectroscopy. This technique exhibited the characteristic bands associated with $\mathrm{F}$ and $\mathrm{F}^{+}$centers defects. The $\mathrm{F}$ centers density was found to increase with the fluence following two different kinetics: a rapid increase for fluences less than $10^{13}$ ions $/ \mathrm{cm}^{2}$ and then, a slow increase for higher fluences. For fluences less than $10^{13}$ ions $/ \mathrm{cm}^{2}$, results are in good agreement with those obtained by Canut et al. [Phys. Rev. B 51 (1995) 12194]. In the fluences range: $10^{13}$ to $10^{14}$ ions $/ \mathrm{cm}^{2}$, the $\mathrm{F}$ centers defects creation process is found to be different from the one evidenced for fluences less than $10^{13}$ ions $/ \mathrm{cm}^{2}$.
\end{abstract}

Pacs Codes: 61.82. Ms ; 65.40.De ; 61.80. $-\mathrm{x}$.

Keywords: Sapphire; Swift heavy ions; Optical absorption; F centers defects.

* Corresponding author: E-Mail : a.nour_kabir@yahoo.fr 


\section{Introduction}

Defects creation and structural transformations induced in sapphire $\left(\alpha-\mathrm{Al}_{2} \mathrm{O}_{3}\right)$ by ion irradiation have been intensively studied by many investigators [1-5]. As a consequence of the energy deposition by projectiles, atoms can be displaced from their equilibrium position either directly by elastic collision or via electronic excitation destroying the local order in a crystalline matrix. Sapphire [6-9], like other materials $\left(\mathrm{LiNbO}_{3}[10,11], \mathrm{Gd}_{3} \mathrm{Ga}_{5} \mathrm{O}_{12}\right.$ [12], $\mathrm{LiF}$ [13] ...), reacts by a change of its volume. Among the defects, created in sapphire by irradiation, are oxygen vacancies, which may contain either two electrons ( $F$ centers), or one electron $\left(\mathrm{F}^{+}\right.$centers). Both defects show optical absorption in the near ultraviolet: at $6.1 \mathrm{eV}$ for $\mathrm{F}$ centers defects and at 4.8 and $5.4 \mathrm{eV}$ for the transitions of the anisotropic $\mathrm{F}^{+}$defects $[14$, 15]. Other absorption feathers have been attributed to $F_{2}$ (Two oxygen vacancies) located at $4.1 \mathrm{eV}, \mathrm{F}_{2}{ }^{+}$(Two oxygen vacancies with three trapped electrons) at $3.49 \mathrm{eV}$ and $\mathrm{F}_{2}{ }^{2+}$ (two oxygen vacancies with two trapped electrons) at $2.7 \mathrm{eV}$ [16-18]. According to Dalal et al. [19], an absorption band located at $6.8 \mathrm{eV}$ is attributed to complex defects of the oxygen sublattice formed in the high damage density cascade caused by heavy ions implants.

In this work, we will show that, at high fluences, the F centers defects production process, in swift heavy ions irradiated sapphire, is different from the one evidenced for low fluences.

\section{Experimental details}

Single crystals of sapphire $\left(\alpha-\mathrm{Al}_{2} \mathrm{O}_{3}\right)$ of $10 \mathrm{~mm}$ diameter and $1 \mathrm{~mm}$ thickness with optical polished surfaces were irradiated with xenon ions after pre-annealing in air at $1723 \mathrm{~K}$ for 120 hours. The irradiations were performed at the IRRSUD facility of the GANIL accelerator (Caen - France) with $0.7 \mathrm{MeV} / \mathrm{amu}$ energy corresponding to an electronic stopping power of $21 \mathrm{keV} / \mathrm{nm}$ and a projected range of $7.6 \mu \mathrm{m}$ (from TRIM2003). Samples were irradiated at room temperature under normal incidence with fluences ranged from $5 \times 10^{11}$ to 2 
$\times 10^{14}$ ions $/ \mathrm{cm}^{2}$. The flux was $\sim 5 \times 10^{8}$ ions $/ \mathrm{cm}^{2}$. s and half of each sample was masked by a thick aluminium foil to stop the incident ions and keep virgin part of samples.

Optical absorption spectra were obtained using a double beam Shimadzu 1700 spectrophotometer in the $190-310 \mathrm{~nm}$ wavelength range. In these experiments, the incident light crossed the sample parallel to the direction of the ion beam and the virgin part spectrum was subtracted from irradiated part spectra. As a result, all the absorption centers induced by the irradiation will contribute to the resulting optical density. The density of $F$ centers per squared centimeter (noted $\mathrm{N}_{\mathrm{F}}$ ) was determined by using the Smakula's formula [21] given by:

$$
N_{F}=2.05 \times 10^{17} \frac{n}{f\left(n^{2}+2\right)^{2}} O D \times W_{1 / 2}
$$

where $f=0.92$ is the oscillator strength of the optical transmission (taken from [15]), $n$ is the refractive index of sapphire at the wavelength corresponding to the absorption band peak and $\mathrm{W}_{1 / 2}$ represents the width (in $\mathrm{eV}$ ) at half maximum of the optical absorption band characterized by a maximum optical density (OD).

\section{Results and discussion}

Optical absorption spectra of irradiated sapphire, in the near ultraviolet wavelength domain, are illustrated in figure.1. The intensity of the absorption band around $6.1 \mathrm{eV}$, which is attributed to F centers defects, increases with the fluence without any shift its position. Its asymmetry could be explained by the presence of the absorption band located at $6.8 \mathrm{eV} \mathrm{[19].}$ Two other weaker bands at 5.4 and $4.8 \mathrm{eV}$, related to $\mathrm{F}^{+}$centers created in the irradiated sapphire, are also found to increase with the fluence. It was found that F centers are easier to produce than $\mathrm{F}^{+}$centers [23] and this agrees with the reported result that $\mathrm{F}$ centers defects were preferentially produced by heavy ions irradiation [5].

Figure. 2 represents the decomposition of a typical optical absorption spectrum by taking into account the presence of the four absorption bands mentioned above. The F center 
density was determined using expression (1) by taking the refractive index $n=1.8$ from [22] and replacing the term $\left(\mathrm{OD} \times \mathrm{W}_{1 / 2}\right)$, in this expression, by the area of the Gaussian used to fit the F centers defects related absorption band. The fluence evolution of the F centers density, shown in figure.3, exhibits two different kinetics: a rapid increase for fluences less than $10^{13}$ ions $/ \mathrm{cm}^{2}$ followed by a slow increase for higher fluences.

In the case of ionic compounds such as alumina, it is considered that the formation of such F-type defect centers of the $\mathrm{F}$ and $\mathrm{F}^{+}$is accompanied with the formation of the interstitial $\mathrm{O}$ and $\mathrm{O}^{-}$respectively. Thus, and in agreement with Moritani et al. [24], the following production mechanism of irradiation induced defects in sapphire can be suggested:

$$
\begin{aligned}
& \mathrm{Al}_{2} \mathrm{O}_{3} \rightarrow \mathrm{Al}_{2} \mathrm{O}_{3}{ }^{*} \rightarrow \mathrm{F}+\mathrm{O} \\
& \mathrm{Al}_{2} \mathrm{O}_{3} \rightarrow \mathrm{Al}_{2} \mathrm{O}_{3}{ }^{*} \rightarrow \mathrm{F}^{+}+\mathrm{O}^{-} \\
& \mathrm{F}+\mathrm{O} \rightarrow \text { recombination } \\
& \mathrm{F}^{+}+\mathrm{O}^{-} \rightarrow \text { recombination } \\
& \mathrm{F}+\mathrm{F} \rightarrow \mathrm{F}_{\mathrm{x}} \\
& \mathrm{F}+\mathrm{F}_{\mathrm{x}} \rightarrow \mathrm{F}_{\mathrm{x}} \\
& \mathrm{F}^{+}+\mathrm{F}_{\mathrm{x}} \rightarrow \mathrm{F}_{\mathrm{x}}
\end{aligned}
$$

Reactions (a) and (b) represent the production of an excited $\mathrm{Al}_{2} \mathrm{O}_{3}\left(\mathrm{Al}_{2} \mathrm{O}_{3}{ }^{*}\right)$ by ion beam irradiation, which is de-excited to $F$ and $F^{+}$. Reactions (c) and (d) represent the recombination of the $\mathrm{F}$ with the $\mathrm{O}$ and the $\mathrm{F}^{+}$with the $\mathrm{O}^{-}$. Reactions (e), (f) and (g) represent the formation of cluster defects (noted $\left.F_{x}\right)$.

Following Canut et al. [20], the major part of $\mathrm{F}$ centers defects is generated by elastic processes near the end of the ion range. We assume that along it's trajectory, each ion creates a number $\mathrm{F}_{0}$ of $\mathrm{F}$ centers defects which is the difference between the created defects and the part of those defects that disappears either by recombination (Reaction (c)) or by cluster 
defects formation (Reactions (e) and (f)). For low fluences, there is no cascade overlap and the F center density varies linearly with the irradiation fluence:

$$
\frac{d N_{F}}{d \Phi}=F_{0}
$$

From the linear fit of the $\mathrm{N}_{\mathrm{F}}$ variation with fluences less than $5 \times 10^{12}$ ions $/ \mathrm{cm}^{2}$ (figure.3), we have deduced that one xenon ion, of $0.7 \mathrm{MeV} / \mathrm{amu}$ energy, creates approximately a number $\mathrm{F}_{0}=3000 \mathrm{~F}$ centers defects which represents $\sim 8 \%$ of displaced atoms calculated using the Kinchin-Pease model [25] with an oxygen displacement energy of $75 \mathrm{eV}$. This result is very close to the value $8.5 \%$ determined by Canut et al. [20] for uranium irradiations in sapphire. The number of F centers defects, compared with the displaced atoms number, is low. In fact, only a fraction of the displaced oxygen atoms generates stable oxygen vacancies, and $\mathrm{F}$ centers are not the only created defects in the irradiated samples, other defects like $\mathrm{F}^{+}$and $\mathrm{F}_{2}$-type centers are also present.

In the fluences range $10^{13}$ to $10^{14}$ ions $/ \mathrm{cm}^{2}$, the $\mathrm{F}$ centers density (figure. 3 ), as well as, the swelling step height and the disordered region thickness (determined from RBS-C spectra) [26], varies linearly with the fluence and this strongly suggests that the disordered layer growth involves also F centers defects creation.

From a linear fit of the swelling step height in this fluences domain (figure.4), the step height increase is $\sim 4.2 \mathrm{~nm}$ per $10^{13}$ ions $/ \mathrm{cm}^{2}$. This value can be compared to the growth velocity $\mathrm{v}=13 \pm 3 \mathrm{~nm}$ per $10^{13}$ ions $/ \mathrm{cm}^{2}$ of the disordered region. Such a step height evolution with the disordered region thickness can be related to density modifications in the near surface region $(\sim 300 \mathrm{~nm})$. If we consider that in this fluences domain, the step height increase corresponds to the volume expansion of the disordered near surface region, we deduce a density decrease of the order of $30 \%$, which is of the order of the density difference between sapphire and alumina. 


\section{Conclusion}

Irradiation of sapphire in a large fluences domain of $0.7 \mathrm{MeV} / \mathrm{amu}$ xenon ions induces disorder; F-type centers defects and swelling of the bombarded surface. In this work, we have evidenced the fluence dependence of the created $\mathrm{F}$ centers defects. The $\mathrm{F}$ centers density, as function of the fluence, evolutes following tow different kinetics: a rapid increase for fluences less than $10^{13}$ ions $/ \mathrm{cm}^{2}$ followed by a slow increase for higher fluences.

In the low fluences domain, results are in good agreement with those obtained by Canut et al. [20] for uranium irradiations. This team has shown that observed effects are related to nuclear energy loss predominating near the end of ions range.

For higher fluences, in the range $10^{13}-10^{14}$ ions $/ \mathrm{cm}^{2}$, comparing with our previous work [26], we observe a correlation between F centers creation, swelling and the near surface region disorder. This fluences domain corresponds to the tracks overlap regime where we have observed, by RBS-C, a near surface structure change. This last could be responsible of the $\mathrm{F}$ centers defects production rate change. It has therefore to be considered that the $\mathrm{F}$ centers defects creation process at high fluences is different from the one evidenced for low fluences.

\section{Acknowledgements}

We are particularly indebted to one of us, Dr. M. Toulemonde, to have placed at our disposal the sapphire samples used in this study. The financial support was provided by the project CMEP, Tassili 03, MDU 573. 


\section{References}

[1] V. A. Skuratov, S. J. Zinkle, A. E. Efimov, K. Havancsak, Surf and Coat. Tech. 196 (2005) 56 .

[2] T. Mohanty, N. C. Mishra, F. Singh, U. Tiwari, D. Kanjilal, Nucl. Instr and Meth. B 212 (2003) 179 .

[3] T. Mohanty, N. C. Mishra, F. Singh, S. V. Bhat, D. Kanjilal, Rad. Meas. 36 (2003) 723.

[4] P. Jonnard, C. Bonnelle, G. Blaise, G. Remond, R. C. Carmes, J. Appl. Phys 88 (2000) 6413.

[5] S. J. Zinkle, Mater Res. Soc. Symp. Proc. 373 (1995) 287.

[6] R. Brenier, B. Canut, S. M. M. Ramos, P. Thévenard, Nucl. Instr. Meth. B 90 (1994) 339.

[7] S. M. M. Ramos, N. Bonardi, B. Canut, S. Della-Negra, Phys. Rev. B 57 (1998) 189.

[8] S. M. M. Ramos, N. Bonardi, B. Canut, S. Bouffard, S. Della-Negra, Nucl. Instr. Meth. B 143 (1998) 319.

[9] Hj. Matzke, Nucl. Instr. Meth. B 116 (1996) 121.

[10] B. Canut, R. Brenier, A. Meftah, P. Moretti, S. Ould Salem, S. M. M. Ramos, P. Thévenard, M. Toulemonde, Nucl. Instr. Meth. B 91 (1994) 312.

[11] B. Canut, S. M. M. Ramos, R. Brenier, P. Thévenard, J. L. Loubet, M. Toulemonde, Nucl. Instr. Meth. B 107 (1996) 194.

[12] M. Toulemonde, A. Meftah, J. M. Costantini, K. Schwartz, C. Trautmann, Nucl. Instr. Meth. B 146 (1998) 426.

[13] C. Trautmann, M. Toulemonde, J. M. Costantini, J. J. Grob, K. Schwartz, Phys. Rev. B $62(2000) 13$.

[14] K. H. Lee and J. H. Crawford, Phys. Rev. B 15 (1977) 4065.

[15] B. D. Evans and M. Stapelbroek, Phys. Rev. B 18 (1978) 7089.

[16] G. J. Poyatshnik, Y. Chen and B. D. Evans, IEEE Trans. Nucl. Sci. NS-34 (1987) 1709. 
[17] L. S. Welch, A. E. Hughes and G. P. Pells, J. Phys. C13 (1980) 1805.

[18] K. H. Lee, G. E. Holmberg and J. H. Crawford, Phys. Stat. Sol. (a) 39 (1977) 669.

[19] M. L. Dalal, M. Rahmani and P. D. Townsend, Nucl. Instr. Meth. B 32 (1988) 61.

[20] B. Canut, A. Benyagoub, G. Marest, A. Meftah, N. Moncoffre, S. M. M. Ramos, F. Studer, P. Thévenard, M. Toulemonde, Phys. Rev. B 51 (1995) 12194.

[21] A. Smakula, Z. F. Phys. 59 (1930) 603.

[22] V. N. Abramov, B. G. Ivanov, A. I. Kuznetsov, Phys. Status Solidi A 48 (1978) 287.

[23] Y. Aoki, T. My Nguen, Y. Shunya, H. Naramoto, Nucl. Instr. Meth. B 114 (1996) 276.

[24] K. Moritani, Y. Teraoka, I. Takagi, M. Akiyoshi and H. Moriyama, Jor. Nucl. Mat. 373 (2007) 157.

[25] G. H. Kinchin and R. S. Pease, Rep. Prog. Phys. 18 (1955) 1.

[26] A. Kabir, A. Meftah, J. P. Stoquert, M. Toulemonde, I. Monnet, Nucl. Instr. Meth. B 266 (2008) 2976 


\section{Figures caption}

Figure.1: Near ultraviolet optical absorption spectra of $0.7 \mathrm{MeV} / \mathrm{amu}$ energy xenon ions irradiated sapphire. Attributed $\mathrm{F}$ and $\mathrm{F}^{+}$centers defects absorption bands are showed.

Figure.2: Gaussians fit for a typical spectrum of optical absorption of $0.7 \mathrm{MeV} / \mathrm{amu}$ energy xenon ions irradiated sapphire

Figure.3: Fluence dependence of the F centers defects density $\left(\mathrm{N}_{\mathrm{F}}\right)$. (Dot line for the linear fit of $\mathrm{N}_{\mathrm{F}}$ at fluences less than $5 \times 10^{12}$ ions $/ \mathrm{cm}^{2}$. Dash line for the linear fit at the fluences range $10^{13}-10^{14}$ ions $/ \mathrm{cm}^{2}$.)

Figure.4: Swelling step height versus the xenon ions fluence for sapphire [26]. Dot line for the swelling step height linear fit at the fluences range $10^{13}-10^{14}$ ions $/ \mathrm{cm}^{2}$. 


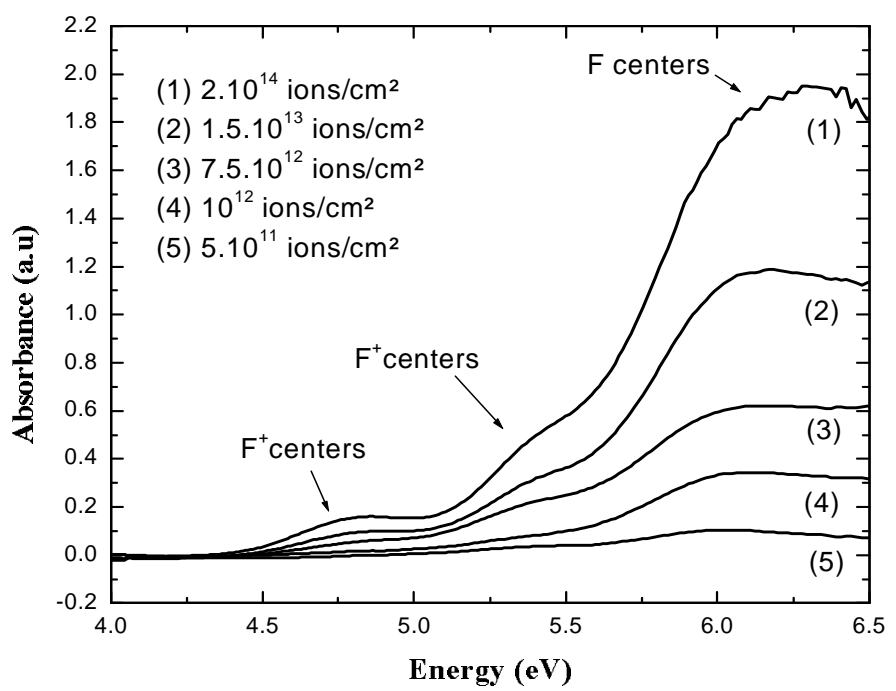

Figure.1 


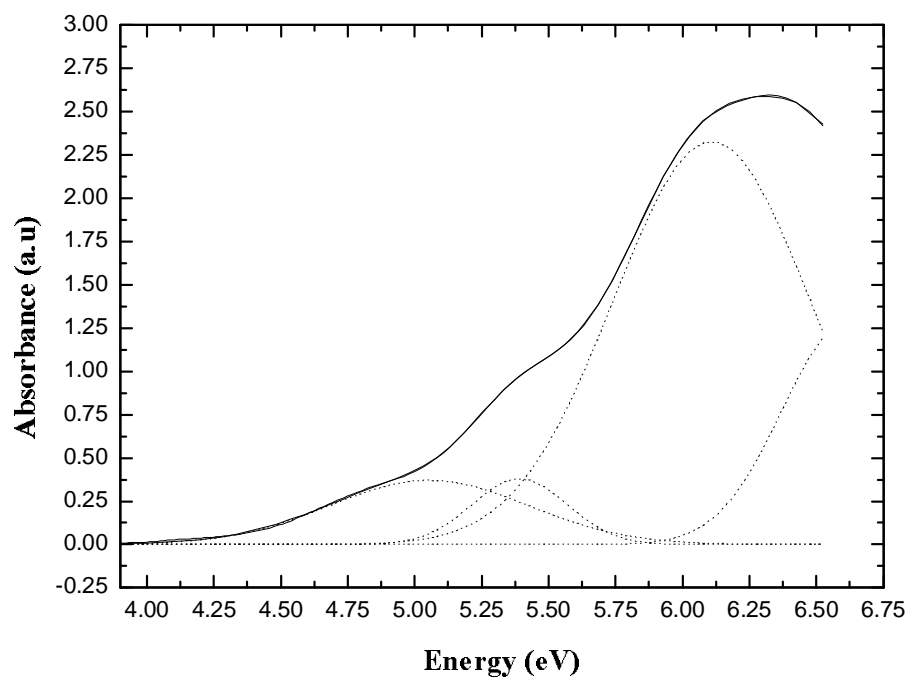

Figure.2 


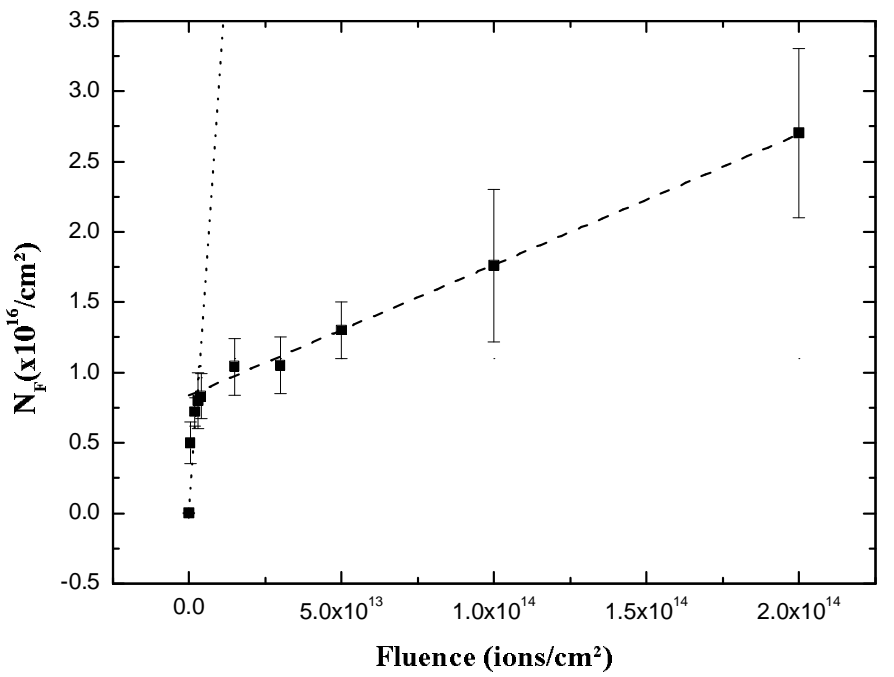

Figure. 3 


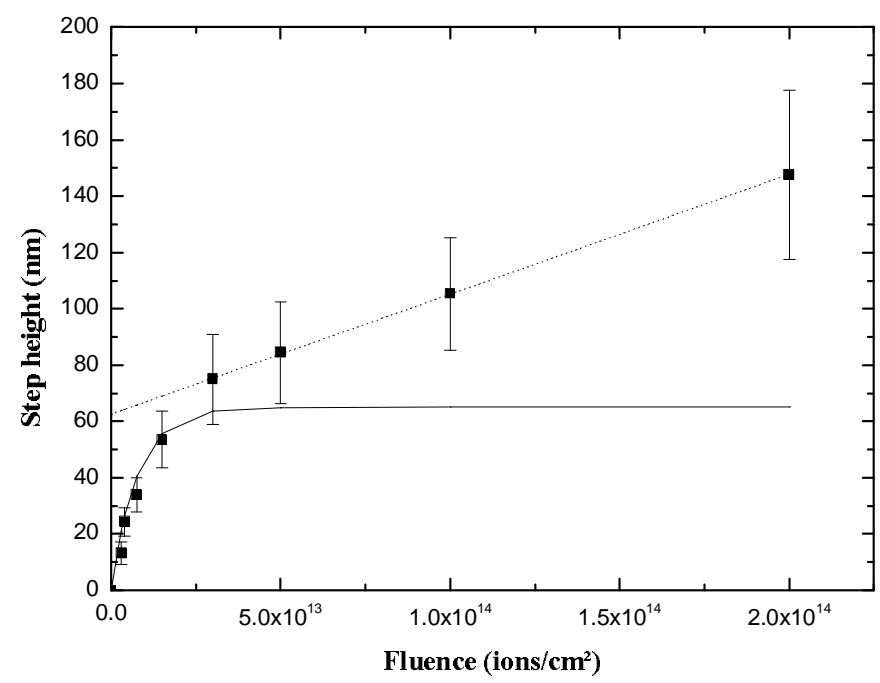

Figure. 4 